\title{
Intensive glycaemic control and cognitive decline in patients with type 2 diabetes: a meta-analysis
}

\author{
Richard H Tuligenga ${ }^{1,2}$ \\ 'IINSERM U1018, Centre for Research in Epidemiology and Population Health, Hôpital Paul Brousse, \\ Bât 15/16, 16 Avenue Paul Vaillant Couturier, 94807 Paris, Villejuif Cedex, France \\ ${ }^{2}$ Université Paris Sud, UMRS 1018 Paris, Villejuif, France
}

\begin{abstract}
The aim of this meta-analysis was to compare the effect of intensive vs standard glycaemic control on cognitive decline in type 2 diabetic patients. A systematic search of PubMed and ALOIS was conducted from inception up to October 30, 2014. Randomised controlled trials (RCTs) of type 2 diabetic patients comparing the rate of change in cognitive function among participants assigned to intensive vs standard glycaemic control were included. An inverse-variance-weighted random effects model was used to calculate standardised mean differences (SMDs) and 95\% Cls. A total of 24297 patients from five RCTs were included in the meta-analysis. Follow-up ranged from 3.3 to 6.2 years. The result from the pooled analysis showed that intensive glycaemic control was not associated with a slower rate of cognitive decline in patients with type 2 diabetes, compared with standard glycaemic control (SMD $=0.02 ; 95 \% \mathrm{Cl}=-0.03$ to 0.08 ) although there was some heterogeneity across individual studies $\left(I^{2}=68 \%, P\right.$ for heterogeneity $\left.=0.01\right)$. There are few diabetes control trials including cognitive endpoints and a small number of trials comparing intensive and standard treatment strategies. Currently, intensive glycaemic control should not be recommended for prevention of cognitive decline in patients with type 2 diabetes because there is no evidence of its effectiveness. Moreover, the use of intensive diabetes treatment results in an increase of risk of hypoglycaemia, which is linked to a greater risk of poor cognition.
\end{abstract}

\section{Introduction}

Patients with type 2 diabetes mellitus show faster cognitive decline compared with healthy subjects (1). Numerous studies in patients with type 2 diabetes have dealt with the association between the level of glycaemic control and the subsequent rate of cognitive decline $(2,3,4,5,6)$, but results are debated (7). Several studies $(8,9,10,11)$ have examined the effect of diabetes treatment on the risk of cognitive decline in type 2 diabetic patients and so far most findings have been inconclusive (12). Recent randomised controlled trials (RCTs) show that intensive glycaemic control does not have beneficial effects on the rate of cognitive decline $(13,14,15,16)$. The increased frequency of hypoglycaemia in patients treated intensively may partially explain the absence of beneficial effects $(13,14,16)$. Hypoglycaemia can occur as a side effect of diabetes treatment and is more frequent in treatments that aim at intensive glycaemic control than in standard glycaemic control (17). A study demonstrates that

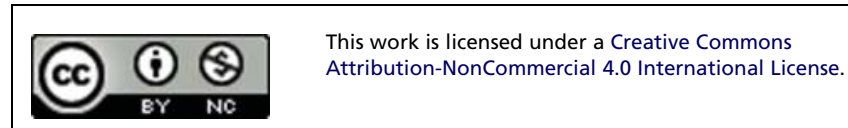


hypoglycaemia is a risk factor for poor cognition (18). In this study, hypoglycaemia was shown to increase the risk of dementia more than two decades later.

Intensive glycaemic control aims at achieving and maintaining glycaemia as close to normal as possible, regardless of the pharmacological therapy used (19). However, glycaemic target level varies across different studies with $\mathrm{HbA1c}$ target levels in the intensive treatment groups ranging between 6.0 and 7.0\%. Standard glycaemic control is less rigid and allows higher HbA1c levels usually between 7.5 and 8.0 (20). The main arguments in favour of the attitude towards intensive treatment of type 2 diabetes are based on the results of the UK Prospective Diabetes Study (UKPDS). This study found that intensive glycaemic control is associated with a reduced risk of microvascular $(21,22)$ and some cardiovascular diseases (CVDs) $(23,24)$. Three recent studies confirmed these beneficial effects, but suggested that intensive glycaemic control does not reduce the risk of CVD in older patients with longstanding type 2 diabetes $(13,25,26)$. As type 2 diabetes affects cognitive function, intensive diabetes control may prevent the onset of microvascular disease in the brain, as well as cognitive decline (27). Thus, restoring a normoglycaemic state could logically mitigate the cognitive effects of type 2 diabetes. However, mixed findings are reported $(10,13,14,15,16,28,29)$ about the effect of intensive glycaemic control when compared with standard glycaemic control on cognitive decline.

Although not all type 2 diabetes linked cognitive decline progresses to dementia (30), the risk of developing dementia is significantly increased (31). Persons with diabetes are 1.5 times more likely to develop Alzheimer's disease and 2.5 times more likely to develop vascular dementia than those without diabetes (32). The presence of gradual cognitive decline over several years before the diagnosis of dementia is well established $(33,34,35)$. Thus, slowing the rate of cognitive decline is especially important for preventing dementia among persons at risk such as diabetic patients, especially as no effective therapeutic treatment of dementia is currently available.

In view of the importance of maintaining cognitive function in type 2 diabetes mellitus and conflicting findings regarding the effect of intensive glycaemic control on subsequent cognitive decline (7), a metaanalysis of RCTs was conducted with the aim to determine whether intensive compared with standard glycaemic control was associated with a slower change in cognitive function over time in type 2 diabetic patients.

\section{Methods}

This meta-analysis was conducted in accordance with the PRISMA guidelines (36).

\section{Search strategy and selection criteria}

A systematic search of the literature up to October 30, 2014 was performed in the PubMed electronic database using the following terms with no restrictions: for the exposure, we used 'intensive glycaemic control' or 'intensive glucose control' or 'diabetes treatment' and, for the outcome, we used 'cognition' or 'cognitive decline' or 'cognitive function'. We also searched ALOIS - the Cochrane Dementia and Cognitive Improvement Group's Specialized Register, where pharmacological interventions in type 2 diabetes patients were selected. Additional separate searches were run in the Cochrane Central Register of Controlled Trials (CENTRAL) and other clinical trial registers to ensure that the search was as comprehensive as possible or to identify unpublished studies. The references included in identified studies were checked for other potentially relevant studies.

Articles that met all the following inclusion criteria were sought and included: randomised, controlled trial study design; enrolment of patients with type 2 diabetes mellitus; comparing two strategies of glycaemic control (intensive and standard) and at least two measures of cognitive function over time.

\section{Data extraction and quality assessment}

Relevant data were extracted from each study. The extracted data included: number of participants, mean age of participants, duration of type 2 diabetes mellitus, persons with a history of CVD, mean of BMI, pre-specified HbA1c levels target in the intervention group, $\mathrm{HbA1}$ c level achieved, mean duration of follow-up, mean rate of cognitive decline in each group or mean difference of rate of cognitive decline.

Quality assessment for studies included in the metaanalysis was determined and internal validity was assessed based on Cochrane Collaboration Criteria (37) for three types of biases: random sequence generation and allocation concealment (selection bias), blinding of assessment of cognitive function (detection bias) and incomplete outcome data (attrition bias).

\section{Data extraction and statistical analysis}

The primary endpoint was the difference in cognitive decline in groups with intensive and standard glycaemic

This work is licensed under a Creative Commons Attribution-NonCommercial 4.0 International License. 
control. Some studies considered cognitive change as a continuous variable and results were presented as $\beta$ coefficients (e.g. as an expression of difference in the rate of change in cognition over time between two groups) or as mean change in cognitive performance in each group. Other trials calculated the risk associated with treatment strategy to detect a specific minimum change in cognition. If the authors reported cognitive decline as a binary variable, we requested continuous data from them. The statistical analyses conducted in each trial also differed across trials. The inconsistency in data reporting and statistical methodology was overcome by calculating the standardised differences of the means (SMDs) and 95\% CI for the $\beta$ coefficients.

For the meta-analysis, Review Manager (RevMan 5.3) was used. The generic inverse variance method (38) was used to group the trials. Each trial is given a weight that is equal to the inverse of the variance of the effect estimate. Thus, large trials that have smaller standard errors are given more weight than smaller trials, which have larger standard errors. This method minimises the imprecision of the pooled effect estimate. A random effect model was

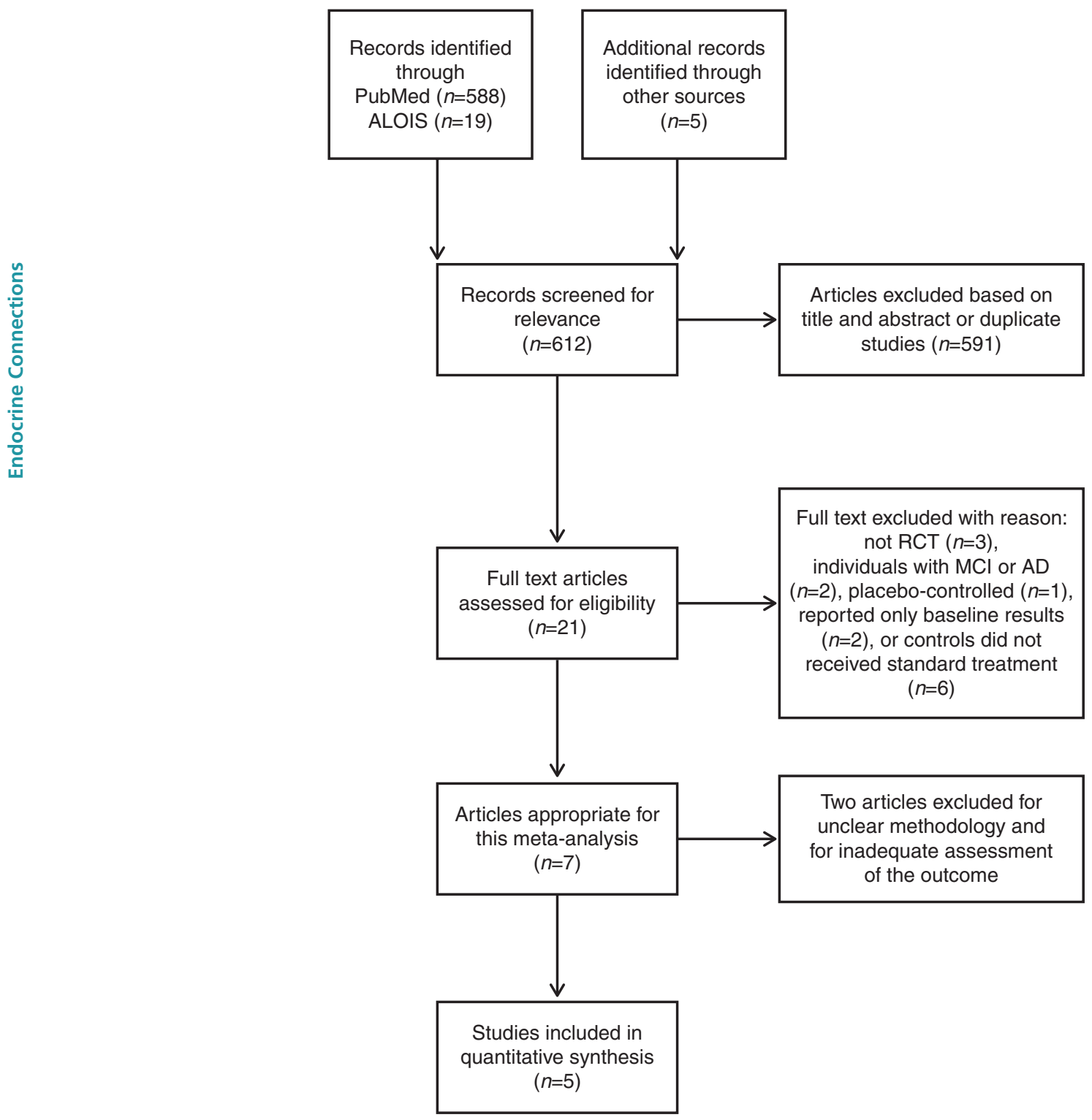

Figure 1

Flowchart of study identification, inclusion and exclusion.

\begin{tabular}{|lr}
\hline http://www.endocrineconnections.org & ( 2015 The authors \\
DOI: 10.1530/EC-15-0004 & Published by Bioscientifica Ltd
\end{tabular}


used to allow for variability among the participants, the type of intervention, control group and outcome definitions. The $\chi^{2}$ test and $I^{2}$ statistics were calculated as a measure to evaluate statistical heterogeneity among studies (39). The test for overall effect ( $z$ statistics with $P$ value) was provided. Sensitivity analyses were conducted based on the specified HbA1c target in the intervention group according to current recommendations; that is, trials with HbA1c target below 7\% or those for which the HbA1c target was 7\% or higher.

\section{Results}

The systematic search of PubMed/Medline and ALOIS database yielded abstracts for 607 publications. Additional searches identified five articles. After reading the titles and abstracts, 591 were excluded as clearly ineligible (mostly not RCT or participants with type 1 diabetes) or were duplicates. Copies of the full published version of each paper were obtained, which were then carefully assessed against inclusion/exclusion criteria. Additional studies were excluded subsequently for the following reasons: participants already suffering from Alzheimer's disease or cognitive impairment, not controlled studies or not randomised studies, cognitive function assessed only at baseline, placebo-controlled study, or controls did not receive standard treatment of diabetes.

Seven studies that evaluated the effects of use of intensive diabetes treatment on cognitive decline in type 2 diabetic patients were identified (Fig. 1). Of these, two studies were excluded subsequently for the following reasons. The first study (10) of 40 diabetic patients was probably underpowered to detect expected adverse effects and did not provide power analysis to estimate the sample size unlike other selected studies. This study had also a short duration of 6 weeks. In the second study (28), cognitive function was assessed by the Cognitive Failure Questionnaire, which is a cognitive test that has been shown to have limitations for the study of cognitive aging and that is not considered to be a reliable test for measuring cognitive function $(40,41)$. Thus, five RCTs were considered for the meta-analysis. For one (13) of these, more information was requested from the authors in order to be able to use the data in the meta-analysis in another form than the one provided in the publication.

Table 1 shows the characteristics extracted from the included trials. These trials included a total of 12165 participants randomised in intensive groups and 12132 randomised in standard groups, with sample sizes in individual studies ranging from 135 to 10320 participants.
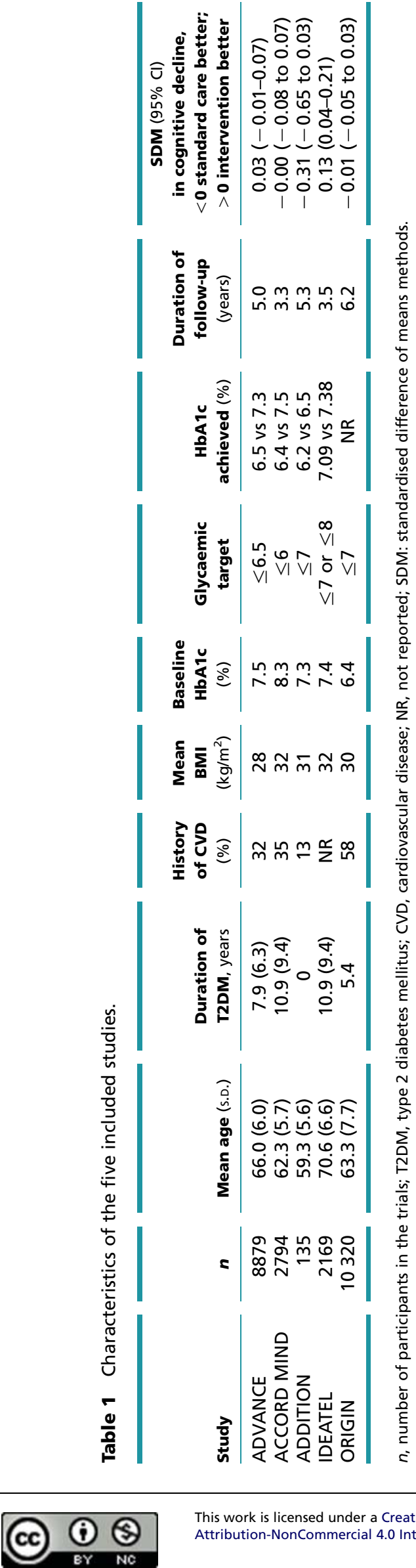

This work is licensed under a Creative Commons Attribution-NonCommercial 4.0 International License. 


\begin{tabular}{|c|c|c|c|c|c|c|}
\hline & & & Intervention & Standard care & & Std. mean difference \\
\hline Study or subgroup & Std. mean difference & S.E.M & Total & Total & Weight (\%) & IV, Random, $95 \% \mathrm{Cl}$ \\
\hline ADVANCE & 0.029 & 0.0212 & 4503 & 4376 & 28.8 & $0.03(-0.01,0.07)$ \\
\hline ACCORD MIND & -0.0042 & 0.0378 & 1378 & 1416 & 20.8 & $-0.00(-0.08,0.07)$ \\
\hline ADDITION & -0.306 & 0.1734 & 71 & 64 & 2.3 & $-0.31(-0.65,0.03)$ \\
\hline IDEATel & 0.1288 & 0.043 & 1093 & 1076 & 18.6 & $0.13(0.04,0.21)$ \\
\hline ORIGIN & -0.0075 & 0.0197 & 5120 & 5200 & 29.5 & $-0.01(-0.05,0.03)$ \\
\hline Total $(95 \% \mathrm{Cl})$ & & & 12165 & 12132 & 100.0 & $0.02(-0.03,0.08)$ \\
\hline
\end{tabular}

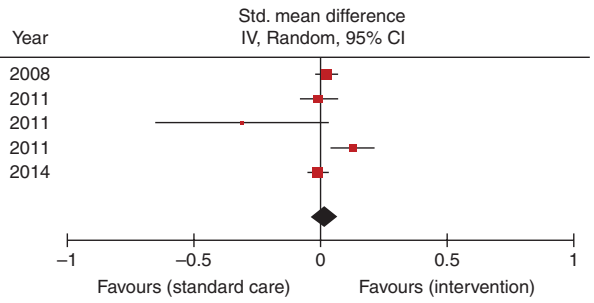

Figure 2

The effect of intensive vs standard glycaemic control on cognitive decline in type 2 diabetic patients.

Baseline mean age of participants at randomisation across studies ranged from 59 to 70 years. The duration of type 2 diabetes mellitus at baseline ranged from 5.4 to 10.8 years, except for one study which included patients with screendetected type 2 diabetes mellitus (15). Three trials selected participants with a higher risk of cardiovascular events $(13,14,16)$. Another trial included elderly patients who were 70 years old on average at randomisation with a relatively well-controlled diabetes (29). In one of the five trials (13), cognition was not a primary outcome. Follow-up periods ranged from 3.3 to 6.2 years.

In four trials, patients receiving intensive treatment showed similar rates of cognitive decline to those assigned to standard treatment. Only one RCT showed that intensive therapy compared with standard therapy was associated with a slower rate of cognitive decline. Figure 2 shows the forest plot of the effect of intensive glycaemic control on the rate of cognitive decline compared with standard glycaemic control. There was no statistical difference between intensive and standard glycaemic control, and significant heterogeneity was found (SDM $0.02 ; 95 \% \mathrm{CI}=-0.03$ to $0.08 ; I^{2}=68 \%, P$ for heterogeneity $=0.01$ )

In sensitivity analysis, the effect of intensive glycaemic control in reducing cognitive decline was assessed based on $\mathrm{HbA1c}$ target in the intervention group at baseline. No difference was reported in two trials with HbA1c target below 7\% in the intervention group and in three trials with
HbA1c target of $7 \%$ or higher. Figure 3 shows pooled results of cognitive decline in patients with intensive HbA1c of $<7 \%$ and Fig. 4 shows pooled results of cognitive decline in patients with intensive HbA1c of 7-8\%.

The quality of studies included in the meta-analysis in terms of randomisation and report of losses to follow-up was generally high (Table 2). Four of the five studies reported the randomisation process, which was adequate in three trials. None of the five trials was double blinded. Follow-up was well documented in all studies.

\section{Discussion}

The results from this meta-analysis indicate that intensive glycaemic control was not associated with an increased or decreased cognitive decline compared with standard glycaemic control in patients with type 2 diabetes. To our knowledge, besides published commentaries (27), this study is the first to analyse clinical trial results on the association between intensive glycaemic control and cognitive decline using a meta-analytic approach.

Overall, there is no evidence of beneficial effects of intensive glycaemic control on cognitive decline. A beneficial effect was observed in only one trial targeting elderly persons with well-controlled type 2 diabetes (29). There are limitations to this study. The improvement in HbA1c was not reported, cognition was evaluated by a test

\begin{tabular}{lrrrrrr} 
& & \multicolumn{3}{c}{ Intervention } & Standard care & \\
Study or subgroup & Std. mean difference & S.E.M & Total & Total & Weight (\%) \\
\hline ADVANCE & 0.029 & 0.0212 & 4503 & 4376 & 76.1 \\
ACCORD MIND & -0.0042 & 0.0378 & 1378 & 1416 & 23.9 \\
& & & 5881 & 5792 & 100.0 \\
Total $(95 \%$ Cl) & & & & & \\
$\begin{array}{l}\text { Heterogeneity: } \tau^{2}=0.00 ; \chi^{2}=0.59, \text { df }=1(P=0.44) ; I^{2}=0 \% \\
\text { Test for overall effect: } Z=1.14(P=0.25)\end{array}$ & & & & &
\end{tabular}

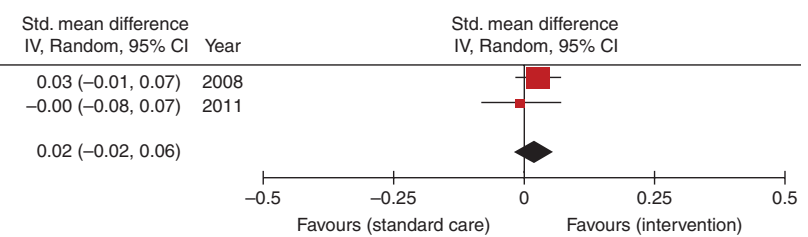

Figure 3

Pooled results of cognitive decline in patients with intensive $\mathrm{HbA} 1 \mathrm{c}$ of $<7 \%$.

http://www.endocrineconnections.org
$\begin{array}{lr}\text { DOI: } 10.1530 / \text { EC-15-0004 } 2015 \text { The authors } \\ \text { Published by Bioscientifica Ltd }\end{array}$




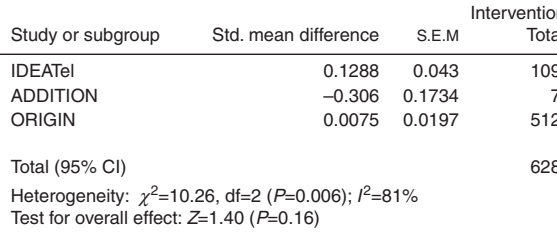

\begin{tabular}{rrr} 
Ton & $\begin{array}{r}\text { Standard care } \\
\text { Total }\end{array}$ & Weight (\%) \\
\hline 093 & 1076 & 17.2 \\
71 & 64 & 1.1 \\
120 & 5200 & 81.8 \\
& & \\
284 & 6340 & 100.0 \\
\hline
\end{tabular}

Test for overall effect: $Z=1.40(P=0.16)$

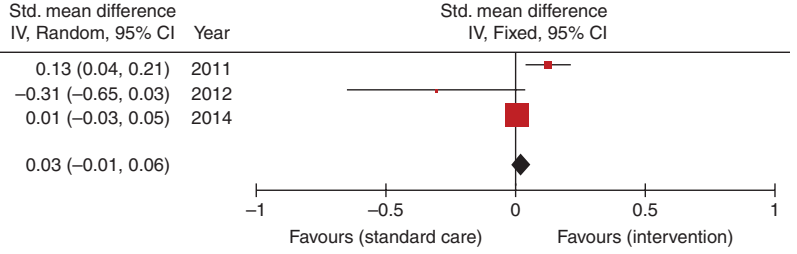

Figure 4

Pooled results of cognitive decline in patients with intensive HbA1c of $7-8 \%$.

designed for dementia screening $(42,43)$ and the effect size was small $(\beta$ coefficient $=-0.03$ and $P=0.01$ ). The results of this trial cannot be generalised because it included highly selected elderly patients (mean age at randomisation $=70.6$ years) who may have a survival benefit. Furthermore, this trial used two targets in the intervention group according to the profile of participants; the HbA1c target of $\leq 7 \%$ was fixed for everyone, except for participants at a high risk of hypoglycaemia for whom the target was of $\leq 8 \%$. The remaining four trials included in the meta-analysis showed that the rate of cognitive decline was similar between intensive and standard glycaemic control groups. Pre-specified HbA1c target may not have any impact on the association between intensive glycaemic control and cognitive decline because there was no difference between trials with $\mathrm{HbA1c}$ target below current recommendations and trials with $\mathrm{HbA1c}$ target of $7 \%$ or higher. Some authors argue that participants randomised to the control group might be motivated by participation in a trial or might receive optimal diabetes care $(14,44)$. This may result in no large differences in healthcare between the intervention and standard treatment groups and may partly explain the lack of effect of the intervention. Note that none of the trials was double blinded. The duration of the interventions was $<10$ years in all trials. Considering the importance of duration of diabetes on cognition $(6,45)$, those interventions may not be long enough to highlight the differences on a phenomenon as complex and multifactorial as cognition.

Intensive glycaemic control has been suggested as important in preventing or delaying microvascular complications of type 2 diabetes mellitus as a result of the UKPDS (23). Three recent trials, Action to Control Cardiovascular Risk in Diabetes (ACCORD) (25), Action in Diabetes and Vascular Disease: Preterax and Diamicron Modified Release Controlled Evaluation (ADVANCE) (13), and Veteran Affairs Diabetes Trial (VADT) (26) confirmed these effects, but the effects on cardiovascular outcomes have been equivocal. These trials reported that intensive glycaemic control reduces microvascular complications, but does not reduce macrovascular complications in older patients with long-standing type 2 diabetes and high cardiovascular risk. As some complications of type 2 diabetes mellitus affect the brain, it is hoped that diabetes treatment may have benefits for cognition. However, the present meta-analysis showed a neutral effect of intensive glycaemic control on the rate of cognitive decline in patients with type 2 diabetes mellitus. It is increasingly clear that hypoglycaemia in intensively treated type 2 diabetic patients may contribute to cognitive decline and explain the absence of beneficial effect of intensive treatment $(13,14,16)$. Hypoglycaemia is more common in intensive glycaemic control than in standard glycaemic control (17). In the ADVANCE trial, high frequency of severe hypoglycaemia was observed in patients with severe

Table 2 Assessment of risk of bias of studies included in meta-analysis.

\begin{tabular}{|c|c|c|c|c|}
\hline Trial & $\begin{array}{l}\text { Random sequence } \\
\text { generation }\end{array}$ & $\begin{array}{l}\text { Allocation } \\
\text { concealment }\end{array}$ & $\begin{array}{l}\text { Blinding of assessment of } \\
\text { cognitive function }\end{array}$ & $\begin{array}{l}\text { Incomplete outcome } \\
\text { data }\end{array}$ \\
\hline ADVANCE & Low & High & Low & Low \\
\hline ACCORD MIND & Low & High & Low & Low \\
\hline ADDITION & Low & High & Low & Low \\
\hline IDEATEL & Unclear & High & Low & Unclear \\
\hline ORIGIN & Low & High & Low & Low \\
\hline
\end{tabular}

http://www.endocrineconnections.org DOI: 10.1530/EC-15-0004
This work is licensed under a Creative Commons Attribution-NonCommercial 4.0 International License. 
cognitive dysfunction (46). Results of the ACCORD MIND trial confirmed this finding, reporting an increase in hypoglycaemic events with use of intensive treatment (25), albeit a HbA1c target of $6.0 \%$ was used in this study. This trial also reported an increased mortality among intensively treated persons. Note that a HbA1c target level of $7 \%$ is recommended by current guidelines for management of type 2 diabetes $(47,48,49)$. In the ORIGIN trial, intensive treatment based on insulin increased hypoglycaemia and modestly increased weight (50).

Hypoglycaemia remains a matter of concern for both clinicians and researchers particularly because the search for optimal glycaemic control to prevent complication of type 2 diabetes mellitus may be limited by the occurrence of hypoglycaemia. This may contribute to therapeutic inertia. There are few studies that have specifically examined the relationship between hypoglycaemia and cognition. A study of more than 1000 patients with type 2 diabetes aged between 60 and 75 years showed an association between self-reported severe hypoglycaemia and poor late-life cognitive abilities (51). Severe hypoglycaemia occurring between 55 and 65 years is a risk factor for incident dementia, as shown by the results from a diabetes registry. In this study, the risk for incident dementia was increased by $26 \%$ in diabetic patients who experienced one severe episode of hypoglycaemia, $80 \%$ for two hypoglycaemia events and $96 \%$ for three or more hypoglycaemia events (18). Inversely, cognitive deficits may also increase the risk of hypoglycaemic events. The Fremantle Diabetes Study showed that dementia was a risk factor for the occurrence of severe hypoglycaemia (52). In the ADVANCE trial, impaired cognitive function predicted severe hypoglycaemic events (46). This suggests a bidirectional relationship.

The major limitation of this meta-analysis was the small number of studies identified. There was a large heterogeneity in baseline characteristics across trials in terms of duration of type 2 diabetes mellitus, history of CVD and glycaemic target. Evidence for a specific antihyperglycaemic agent is lacking because the effects of different classes of antihyperglycaemic agents compared with each other were not reported in these trials.

In conclusion, this meta-analysis summarised the results of RCTs comparing the effect of intensive and standard glycaemic control on the rate of cognitive decline. The results suggest that intensive glycaemic control does not reduce the rate of cognitive decline in type 2 diabetic patients. Moreover, the use of intensive glycaemic control results in an increase in the risk of hypoglycaemia. Further treatment strategies to maintain cognitive function in type 2 diabetic patients with greater consideration of neurological consequences of hypoglycaemic events in the long term should be investigated.

\section{Declaration of interest}

The author declare that there is no conflict of interest that could be perceived as prejudicing the impartiality of this review.

\section{Funding}

This review did not receive any specific grant from any funding agency in the public, commercial or not-for-profit sector.

\section{References}

1 Cukierman T, Gerstein HC \& Williamson JD. Cognitive decline and dementia in diabetes - systematic overview of prospective observational studies. Diabetologia 200548 2460-2469. (doi:10.1007/ s00125-005-0023-4)

2 Ryan CM \& Geckle MO. Circumscribed cognitive dysfunction in middle-aged adults with type 2 diabetes. Diabetes Care 200023 1486-1493. (doi:10.2337/diacare.23.10.1486)

3 Kanaya AM, Barrett-Connor E, Gildengorin G \& Yaffe K. Change in cognitive function by glucose tolerance status in older adults: a 4-year prospective study of the Rancho Bernardo study cohort. Archives of Internal Medicine 2004164 1327-1333. (doi:10.1001/archinte.164.12.1327)

4 Cukierman-Yaffe T, Gerstein HC, Williamson JD, Lazar RM, Lovato L, Miller ME, Coker LH, Murray A, Sullivan MD, Marcovina SM et al. Relationship between baseline glycemic control and cognitive function in individuals with type 2 diabetes and other cardiovascular risk factors: the action to control cardiovascular risk in diabetes-memory in diabetes (ACCORD-MIND) trial. Diabetes Care 200932 221-226. (doi:10.2337/ dc08-1153) (doi:10.2337/dc08-1153)

5 Maggi S, Limongi F, Noale M, Romanato G, Tonin P, Rozzini R, Scafato E, Crepaldi G \& ILSA Study Group. Diabetes as a risk factor for cognitive decline in older patients. Dementia and Geriatric Cognitive Disorders 200927 24-33. (doi:10.1159/000183842)

6 Tuligenga RH, Dugravot A, Tabák AG, Elbaz A, Brunner EJ, Kivimäki M $\&$ Singh-Manoux A. Midlife type 2 diabetes and poor glycaemic control as risk factors for cognitive decline in early old age: a post-hoc analysis of the Whitehall II cohort study. Lancet. Diabetes \& Endocrinology 20142 228-235. (doi:10.1016/S2213-8587(13)70192-X)

7 Geijselaers SL, Sep SJ, Stehouwer CD \& Biessels GJ. Glucose regulation, cognition, and brain MRI in type 2 diabetes: a systematic review. Lancet. Diabetes \& Endocrinology 20143 75-89. (doi:10.1016/S22138587(14)70148-2)

8 Gradman TJ, Laws A, Thompson LW \& Reaven GM. Verbal learning and/or memory improves with glycemic control in older subjects with non-insulin-dependent diabetes mellitus. Journal of the American Geriatrics Society 199341 1305-1312.

9 Meneilly GS, Cheung E, Tessier D, Yakura C \& Tuokko H. The effect of improved glycemic control on cognitive functions in the elderly patient with diabetes. Journal of Gerontology 199348 M117-M121. (doi:10.1093/geronj/48.4.M117)

10 Naor M, Steingrüber HJ, Westhoff K, Schottenfeld-Naor Y \& Gries AF. Cognitive function in elderly non-insulin-dependent diabetic patients before and after inpatient treatment for metabolic control. Journal of Diabetes and its Complications 199711 40-46. (doi:10.1016/10568727(95)00106-9)

11 Ryan CM, Freed MI, Rood JA, Cobitz AR, Waterhouse BR \& Strachan MW. Improving metabolic control leads to better working 
memory in adults with type 2 diabetes. Diabetes Care 200629 345-351. (doi:10.2337/diacare.29REF6=10.1016/S2213-8587(13)70192-X)

12 Areosa SA \& Grimley EV. Effect of the treatment of type II diabetes mellitus on the development of cognitive impairment and dementia. Cochrane Database of Systematic Reviews 20024 1-22. CD003804. (doi:10.1002/14651858.CD003804)

13 ADVANCE Collaborative Group , Patel A, MacMahon S, Chalmers J, Neal B, Billot L, Woodward M, Marre M, Cooper M, Glasziou P et al. Intensive blood glucose control and vascular outcomes in patients with type 2 diabetes. New England Journal of Medicine 2008358 2560-2572. (doi:10.1056/NEJMoa0802987)

14 Launer LJ, Miller ME, Williamson JD, Lazar RM, Gerstein HC, Murray AM, Sullivan M, Horowitz KR, Ding J, Marcovina S et al. Effects of intensive glucose lowering on brain structure and function in people with type 2 diabetes (ACCORD MIND): a randomised open-label substudy. Lancet. Neurology 201110 969-977. (doi:10.1016/S14744422(11)70188-0)

15 Koekkoek PS, Ruis C, van den Donk M, Biessels GJ, Gorter KJ, Kappelle LJ \& Rutten GE. Intensive multifactorial treatment and cognitive functioning in screen-detected type 2 diabetes - the ADDITION-Netherlands study: a cluster-randomized trial. Journal of the Neurological Sciences 2012314 71-77. (doi:10.1016/j.jns.2011.10.028)

16 Cukierman-Yaffe T, Bosch J, Diaz R, Dyal L, Hancu N, Hildebrandt P, Lanas F, Lewis BS, Marre M, Yale JF et al. Effects of basal insulin glargine and omega-3 fatty acid on cognitive decline and probable cognitive impairment in people with dysglycaemia: a substudy of the ORIGIN trial. Lancet. Diabetes \& Endocrinology 20142 562-572. (doi:10.1016/ S2213-8587(14)70062-2)

17 Chatterjee S, Sharma A, Lichstein E \& Mukherjee D. Intensive glucose control in diabetics with an acute myocardial infarction does not improve mortality and increases risk of hypoglycemia-a metaregression analysis. Current Vascular Pharmacology 201311 100-104. (doi:10.2174/157016113804547548)

18 Whitmer RA, Karter AJ, Yaffe K, Quesenberry CP \& Selby JV. Hypoglycemic episodes and risk of dementia in older patients with type 2 diabetes mellitus. Journal of the American Medical Association 2009 301 1565-1572. (doi:10.1001/jama.2009.460)

19 ACE/ADA Task Force on Inpatient Diabetes. American College of Endocrinology and American Diabetes Association consensus statement on inpatient diabetes and glycemic control. Endocrine Practice 200612 (Suppl 3) 4-13. (doi:10.4158/EP.12.4.458)

20 Hemmingsen B, Lund SS, Gluud C, Vaag A, Almdal T, Hemmingsen C \& Wetterslev J. Targeting intensive glycaemic control versus targeting conventional glycaemic control for type 2 diabetes mellitus. Cochrane Database of Systematic Reviews 201311 CD008143. (doi:10.1002/ 14651858.CD008143.pub3)

21 Intensive blood-glucose control with sulphonylureas or insulin compared with conventional treatment and risk of complications in patients with type 2 diabetes (UKPDS 33). UK Prospective Diabetes Study (UKPDS) Group. Lancet 1998352 837-853. (doi:10.1016/S01406736(98)07019-6)

22 Effect of intensive blood-glucose control with metformin on complications in overweight patients with type 2 diabetes (UKPDS 34). UK Prospective Diabetes Study (UKPDS) Group. Lancet 1998352 854-865. (doi:10.1016/S0140-6736(98)07037-8)

23 Holman RR, Paul SK, Bethel MA, Matthews DR \& Neil HAW. 10-year followup of intensive glucose control in type 2 diabetes. New England Journal of Medicine 2008359 1577-1589. (doi:10.1056/NEJMoa0806470)

24 Reaven PD, Moritz TE, Schwenke DC, Anderson RJ, Criqui M, Detrano R, Emanuele N, Kayshap M, Marks J, Mudaliar S et al. Intensive glucoselowering therapy reduces cardiovascular disease events in veterans affairs diabetes trial participants with lower calcified coronary atherosclerosis. Diabetes 200958 2642-2648. (doi:10.2337/db09-0618)

25 Action to Control Cardiovascular Risk in Diabetes Study Group, Gerstein HC, Miller ME, Byington RP, Goff DC Jr, Bigger JT, Buse JB, Cushman WC, Genuth S, Ismail-Beigi F et al. Effects of intensive glucose lowering in type 2 diabetes. New England Journal of Medicine 2008358 2545-2559. (doi:10.1056/NEJMoa0802743)

26 Control Group, Turnbull FM, Abraira C, Anderson RJ, Byington RP, Chalmers JP, Duckworth WC, Evans GW, Gerstein HC, Holman RR et al. Intensive glucose control and macrovascular outcomes in type 2 diabetes. Diabetologia 200952 2288-2298. (doi:10.1007/s00125-009-1470-0)

27 Kawamura T, Umemura T \& Hotta N. Cognitive impairment in diabetic patients: can diabetic control prevent cognitive decline? Journal of Diabetes Investigation 20123 413-423. (doi:10.1111/j.2040-1124.2012.00234.x)

28 Quality of life in type 2 diabetic patients is affected by complications but not by intensive policies to improve blood glucose or blood pressure control (UKPDS 37). UK Prospective Diabetes Study Group. Diabetes Care 199922 1125-1136. (doi:10.2337/diacare.22.7.1125)

29 Luchsinger JA, Palmas W, Teresi JA, Silver S, Kong J, Eimicke JP, Weinstock RS \& Shea S. Improved diabetes control in the elderly delays global cognitive decline. Journal of Nutrition, Health \& Aging 201115 445-449. (doi:10.1007/s12603-011-0057-x)

30 Biessels GJ, Deary IJ \& Ryan CM. Cognition and diabetes: a lifespan perspective. Lancet. Neurology 20087 184-190. (doi:10.1016/S14744422(08)70021-8)

31 Velayudhan L, Poppe M, Archer N, Proitsi P, Brown RG \& Lovestone S. Risk of developing dementia in people with diabetes and mild cognitive impairment. British Journal of Psychiatry 2010196 36-40. (doi:10.1192/ bjp.bp.109.067942)

32 Cheng C, Lin CH, Tsai YW, Tsai CJ, Chou PH \& Lan TH. Type 2 diabetes and antidiabetic medications in relation to dementia diagnosis. Journals of Gerontology. Series A, Biological Sciences and Medical Sciences 201469 1299-1305. (doi:10.1093/gerona/glu073)

33 Amieva H, Le Goff M, Millet X, Orgogozo JM, Pérès K, BarbergerGateau P, Jacqmin-Gadda H \& Dartigues JF. Prodromal Alzheimer's disease: successive emergence of the clinical symptoms. Annals of Neurology 200864 492-498. (doi:10.1002/ana.21509)

34 Brayne C. The elephant in the room - healthy brains in later life, epidemiology and public health. Nature Reviews. Neuroscience $2007 \mathbf{8}$ 233-239. (doi:10.1038/nrn2091)

35 Hachinski V. Shifts in thinking about dementia. Journal of the American Medical Association 2008300 2172-2173. (doi:10.1001/jama.2008.525)

36 Moher D, Liberati A, Tetzlaff J, Altman DG \& PRISMA Group . Preferred reporting items for systematic reviews and meta-analyses: the PRISMA statement. International Journal of Surgery 20108 336-341. (doi:10.1016/ j.ijsu.2010.02.007)

37 Higgins JPT, Altman DG, Gøtzsche PC, Jüni P, Moher D, Oxman AD, Savovic J, Schulz KF, Weeks L, Sterne JA et al. The Cochrane Collaboration's tool for assessing risk of bias in randomised trials. BMJ 2011343 d5928. (doi:10.1136/bmj.d5928)

38 Deeks JJ, Higgins JPT, Altman DG. Analysing and presenting results. In: Cochrane Handbook for Systematic Reviews of Interventions 4.2.6 (updated September 2006) Eds JP Higgins, S Green. Section 8. In The Cochrane Library, Issue 4, 2006. Chichester, UK: John Wiley \& Sons Ltd, 2006.

39 Higgins JP, Thompson SG, Deeks JJ \& Altman DG. Measuring inconsistency in meta-analyses. BMJ 2003327 557-560. (doi:10.1136/ bmj.327.7414.557)

40 Matthews G, Coyle K \& Craig A. Multiple factors of cognitive failure and their relationship with stress vulnerability. Journal of Psychopathology and Behavioral Assessment 199012 49-65. (doi:10.1007/ BF00960453)

41 Wagle AC, Berrios GE \& Ho L. The cognitive failures questionnaire in psychiatry. Comprehensive Psychiatry 199940 478-484. (doi:10.1016/ S0010-440X(9REF41=10.1016/S0010-440X(99)90093-7)

42 Gurland B, Kuriansky J, Sharpe L, Simon R, Stiller P \& Birkett P. The comprehensive assessment and referral evaluation (CARE)-rationale, development and reliability. International Journal of Aging \& Human Development 19778 9-42. (doi:10.2190/CL3J-0E20-97XX-MV5L)

43 Gurland B, Wilder D, Cross P, Teresi J \& Barrett V. Screening scales for dementia: towards reconciliation of conflicting cross-cultural findings. 
International Journal of Geriatric Psychiatry 19927 105-113.

(doi:10.1002/gps.930070207)

44 The effect of intensive treatment of diabetes on the development and progression of long-term complications in insulin-dependent diabetes mellitus. The Diabetes Control and Complications Trial Research Group. New England Journal of Medicine 1993329 977-986. (doi:10. 1056/NEJM199309303291401)

45 Rawlings AM, Richey Sharrett A, Schneider AL, Coresh J, Albert M, Couper D, Griswold M, Gottesman RF, Wagenknecht LE, Windham BG et al. Diabetes in midlife and cognitive change over 20 years: a cohort study. Annals of Internal Medicine 2014161 785-793. (doi:10.7326/M14-0737)

46 De Galan BE, Zoungas S, Chalmers J, Anderson C, Dufouil C, Pillai A, Cooper M, Grobbee DE, Hackett M, Hamet P et al. Cognitive function and risks of cardiovascular disease and hypoglycaemia in patients with type 2 diabetes: the Action in Diabetes and Vascular Disease: Preterax and Diamicron Modified Release Controlled Evaluation (ADVANCE) trial. Diabetologia 200952 2328-2336. (doi:10.1007/ s00125-009-1484-7)

47 Clinical IDF \& Guidelines Task Force. Global Guideline for Type 2 Diabetes: recommendations for standard, comprehensive, and minimal care. Diabetic Medicine 200623 579-593. (doi:10.1111/j.1464-5491. 2006.01918.x)
48 American Diabetes Association. Standards of medical care in diabetes 2007. Diabetes Care 200730 (Suppl 1) S4-S41. (doi:10.2337/dc07-S004)

49 Rydén L, Standl E, Bartnik M, Van den Berghe G, Betteridge J, de Boer MJ, Cosentino F, Jönsson B, Laakso M, Malmberg K et al. Guidelines on diabetes, pre-diabetes, and cardiovascular diseases: executive summary. The Task Force on Diabetes and Cardiovascular Diseases of the European Society of Cardiology (ESC) and of the European Association for the Study of Diabetes (EASD). European Heart Journal 200728 88-136. (doi:10.1093/eurheartj/ehl260)

50 ORIGIN Trial Investigators , Gerstein HC, Bosch J, Dagenais GR, Díaz R, Jung H, Maggioni AP, Pogue J, Probstfield J, Ramachandran A et al. Basal insulin and cardiovascular and other outcomes in dysglycemia. New England Journal of Medicine 2012367 319-328. (doi:10.1056/ NEJMoa1203858)

51 Aung PP, Strachan MW, Frier BM, Butcher I, Deary IJ \& Price JF. Edinburgh Type 2 Diabetes Study investigators, severe hypoglycaemia and late-life cognitive ability in older people with type 2 diabetes: the Edinburgh Type 2 Diabetes Study. Diabetic Medicine 201229 328-336. (doi:10REF50=10.1056/NEJMoa1203858)

52 Bruce DG, Davis WA, Casey GP, Clarnette RM, Brown SG, Jacobs IG, Almeida OP \& Davis TM. Severe hypoglycaemia and cognitive impairment in older patients with diabetes: the Fremantle Diabetes Study. Diabetologia 200952 1808-1815. (doi:10.1007/s00125-009-1437-1)

Received in final form 19 February 2015

Accepted 23 February 2015 http://www.endocrineconnections.org DOI: 10.1530/EC-15-0004
(C) 2015 The authors Published by Bioscientifica Ltd
This work is licensed under a Creative Commons Attribution-NonCommercial 4.0 International License. 